\section{Olmesartan for the Delay or Prevention of Microalbuminuria in Type 2 Diabetes}

\author{
Hermann Haller, M.D., Sadayoshi Ito, M.D., Ph.D., Joseph L. Izzo, Jr., M.D., \\ Andrzej Januszewicz, M.D., Shigehiro Katayama, M.D., Ph.D., Jan Menne, M.D., \\ Albert Mimran, M.D., Ton J. Rabelink, M.D., Ph.D., Eberhard Ritz, M.D., \\ Luis M. Ruilope, M.D., Lars C. Rump, M.D., and Giancarlo Viberti, M.D., \\ for the ROADMAP Trial Investigators*
}

ABSTRACT

\section{BACKGROUND}

Microalbuminuria is an early predictor of diabetic nephropathy and premature cardiovascular disease. We investigated whether treatment with an angiotensin-receptor blocker (ARB) would delay or prevent the occurrence of microalbuminuria in patients with type 2 diabetes and normoalbuminuria.

\section{METHODS}

In a randomized, double-blind, multicenter, controlled trial, we assigned 4447 patients with type 2 diabetes to receive olmesartan (at a dose of $40 \mathrm{mg}$ once daily) or placebo for a median of 3.2 years. Additional antihypertensive drugs (except angiotensin-converting-enzyme inhibitors or ARBs) were used as needed to lower blood pressure to less than $130 / 80 \mathrm{~mm} \mathrm{Hg}$. The primary outcome was the time to the first onset of microalbuminuria. The times to the onset of renal and cardiovascular events were analyzed as secondary end points.

\section{RESULTS}

The target blood pressure $(<130 / 80 \mathrm{~mm} \mathrm{Hg}$ ) was achieved in nearly $80 \%$ of the patients taking olmesartan and $71 \%$ taking placebo; blood pressure measured in the clinic was lower by $3.1 / 1.9 \mathrm{~mm} \mathrm{Hg}$ in the olmesartan group than in the placebo group. Microalbuminuria developed in $8.2 \%$ of the patients in the olmesartan group (178 of 2160 patients who could be evaluated) and $9.8 \%$ in the placebo group (210 of 2139); the time to the onset of microalbuminuria was increased by $23 \%$ with olmesartan (hazard ratio for onset of microalbuminuria, $0.77 ; 95 \%$ confidence interval, 0.63 to 0.94; $\mathrm{P}=0.01$ ). The serum creatinine level doubled in $1 \%$ of the patients in each group. Slightly fewer patients in the olmesartan group than in the placebo group had nonfatal cardiovascular events - 81 of 2232 patients (3.6\%) as compared with 91 of 2215 patients $(4.1 \%)(\mathrm{P}=0.37)$ - but a greater number had fatal cardiovascular events -15 patients $(0.7 \%)$ as compared with 3 patients $(0.1 \%)(\mathrm{P}=0.01)$, a difference that was attributable in part to a higher rate of death from cardiovascular causes in the olmesartan group than in the placebo group among patients with preexisting coronary heart disease (11 of 564 patients [2.0\%] vs. 1 of 540 [0.2\%], $\mathrm{P}=0.02$ ).

\section{CONCLUSIONS}

Olmesartan was associated with a delayed onset of microalbuminuria, even though blood-pressure control in both groups was excellent according to current standards. The higher rate of fatal cardiovascular events with olmesartan among patients with preexisting coronary heart disease is of concern. (Funded by Daiichi Sankyo; ClinicalTrials.gov number, NCT00185159.)
From the Department of Nephrology and Hypertension, Hannover Medical School, Hannover (H.H., J.M.); the Department of Nephrology, University of Heidelberg, Heidelberg (E.R.); and the Department of Nephrology, HeinrichHeine-University Düsseldorf (L.C.R.) all in Germany; the Department of Clinical Medicine, Division of Nephrology, Endocrinology, and Vascular Medicine, Tohoku University Graduate School of Medicine, Sendai (S.I.); and the Department of Endocrinology and Diabetes, Saitama Medical School, Iruma, Saitama (S.K.) - both in Japan; the Department of Medicine, School of Medicine and Biomedical Sciences, State University of New York at Buffalo, Buffalo (J.L.I.); the Institute of Cardiology, Department of Hypertension, Warsaw, Poland (A.J.); Hospital Lapeyronie, Montpellier, France (A.M.); the Department of Nephrology and Einthoven Laboratory for Vascular Medicine, Leiden University Medical Center, Leiden, the Netherlands (T.J.R.); the Division of Hypertension, Hospital 12 de Octubre, Madrid (L.M.R.); and King's College London School of Medicine, Guy's Hospital, London (G.V.). Address reprint requests to Dr. Haller at the Department of Nephrology and Hypertension, Hannover Medical School, CarlNeuberg Str. 1, 30625 Hannover, Germany, or at haller.hermann@mh-hannover.de.

\section{*The investigators in the Randomized Olmesartan and Diabetes Microalbu- minuria Prevention (ROADMAP) trial are listed in the Supplementary Appen- dix, available at NEJM.org.}

N Engl J Med 2011;364:907-17.

Copyright (C) 2011 Massachusetts Medical Society. 
IABETIC NEPHROPATHY IS AN INCREASingly common cause of end-stage renal disease, ${ }^{1}$ and the development and rate of renal deterioration are most closely related to the patient's blood pressure. Guideline committees worldwide concur that the blood pressure in patients with diabetes and chronic kidney disease should be kept at $130 / 80 \mathrm{~mm}$ Hg or less. ${ }^{2}$ Microalbuminuria is predictive of diabetic nephropathy and premature cardiovascular disease $\mathrm{e}^{3-5}$; therefore, European and American guidelines recommend that patients with diabetes be tested for microalbuminuria. ${ }^{6,7}$

Overactivity of the renin-angiotensin system has been implicated in the deterioration of renal function in patients with diabetic nephropathy and in patients who have stage 3 or 4 chronic kidney disease with microalbuminuria or macroalbuminuria. ${ }^{8,9}$ Angiotensin-converting-enzyme (ACE) inhibitors and angiotensin-receptor blockers (ARBs) slow the worsening of the glomerular filtration rate (GFR) and lower the rate of albumin excretion. Treatment at an early stage of the disease may be beneficial. ACE inhibition delays the onset of microalbuminuria in patients with hypertension, type 2 diabetes, normoalbuminuria, and normal renal function. ${ }^{10}$ Whether similar benefits occur when ARB therapy is begun early in the course of diabetes is unknown. ${ }^{11,12}$

In the Randomized Olmesartan and Diabetes Microalbuminuria Prevention (ROADMAP) study, we tested whether olmesartan medoxomil (Benicar, Daiichi Sankyo), at a dose of $40 \mathrm{mg}$ daily, as compared with placebo, prevents or delays the time to the first occurrence of microalbuminuria in patients who have type 2 diabetes, as well as at least one other cardiovascular risk factor, and normoalbuminuria. Blood-pressure control ( $<130 / 80 \mathrm{~mm} \mathrm{Hg}$ ) in both groups was achieved by adding, as needed, antihypertensive agents that do not block the renin-angiotensin system.

\section{METHODS}

STUDY DESIGN AND ORGANIZATION

The study design has been published previously. ${ }^{13}$ The sponsor (Daiichi Sankyo) had no role in the design or conduct of the study, but representatives of the sponsor served as nonvoting members of the steering committee. Statistical analyses were performed by a clinical research organization, with confirmation by biostatisticians who were employees of the sponsor. The authors had complete control over the analysis and interpretation of the results, the writing of the manuscript, and the decision to submit it for publication, and they vouch for the accuracy and completeness of the reported data, as well as the fidelity of the reported study to the protocol. The study protocol, including the statistical analysis plan, is available with the full text of this article at NEJM.org.

We conducted this randomized, double-blind, placebo-controlled, parallel-group, multicenter phase 3b study at 262 collaborating centers in 19 European countries. The ethics committee at each participating center approved the study, and written informed consent was obtained from each patient. The study enrolled patients with type 2 diabetes, among whom there was a wide range of blood-pressure values, including some that were in the normal range. Patients who had used ACE inhibitors or ARBs during the 6 months before the start of the study were excluded. Treatment with ACE inhibitors and ARBs (other than olmesartan in the experimental group) was not allowed at any time during the study; during the doubleblind treatment phase, other antihypertensive agents were allowed in both groups to help patients reach and maintain the target blood pressure of less than $130 / 80 \mathrm{~mm} \mathrm{Hg}$.

\section{STUDY POPULATION}

A total of 4449 white patients, 18 to 75 years of age, who had type 2 diabetes underwent randomization. A summary of the main inclusion and exclusion criteria and an overview of the screening, enrollment, randomization, and follow-up are shown in Tables 1 and 2 in the Supplementary Appendix, available at NEJM.org. After the screening phase, each patient's eligibility for the study was established during a prerandomization phase (maximum duration, 4 weeks), during which normoalbuminuria was confirmed by means of two additional measurements of morning spot urine samples.

\section{END POINTS}

The primary end point was the time to the first onset of microalbuminuria, as determined by validated measurements of morning spot urine samples. Microalbuminuria was defined as a urinary albumin-to-creatinine ratio (with albumin measured in milligrams and creatinine measured in grams) of more than 35 in women or more than 
25 in men. Any single elevation in the urinary albumin-to-creatinine ratio required confirmation by at least one additional positive result from two separate tests of urine samples performed within 2 weeks after the initial test. If microalbuminuria was confirmed, the patient was assigned to an open-label phase in which he or she received olmesartan at a dose of $40 \mathrm{mg}$ daily (Fig. 1 in the Supplementary Appendix). At each follow-up visit, a spot urine sample was obtained, and blood pressure was measured with an automatic device. The blood-pressure measurement that was used was the mean of three values recorded 3 minutes apart. If the blood pressure was $130 / 80 \mathrm{~mm} \mathrm{Hg}$ or higher, the protocol called for adjustment of the antihypertensive medication (excluding the use of blockers of the renin-angiotensin system or aldosterone blockers). A central laboratory (CRL-Medinet) determined the urinary albumin-to-creatinine ratio and all other laboratory variables. Secondary end points included a composite of cardiovascular complications and death from cardiovascular causes (Table 3 in the Supplementary Appendix) and renal events.

\section{STATISTICAL ANALYSIS}

A total of 4447 of the 4449 patients who underwent randomization were included in the intention-to-treat analysis; 2 patients who underwent randomization never took a study medication (Table 2A in the Supplementary Appendix). The baseline urinary albumin-to-creatinine ratio was the geometric mean of three measurements obtained during the randomization phase (up to visit 1). A confirmatory analysis of the primary efficacy end point was performed with the use of a Cox proportional-hazards regression model with treatment as a fixed effect; the baseline urinary albumin-to-creatinine ratio was logarithmically transformed (base 10) as a covariate, and a twotailed Wald chi-square test was performed with an alpha level of less than 0.05; hazard ratios and two-sided $95.1 \%$ confidence intervals were calculated. (Owing to a prespecified interim analysis performed by the data and safety monitoring board, the significance level for the final confirmatory analysis was adjusted to 0.049 , resulting in a two-sided $95.1 \%$ confidence interval.) To account for all patients who entered the doubleblind treatment period, the last assessment that was performed before patients left the doubleblind period was used as the last time point. All statistical analyses were performed with the use of SAS software for Windows, version 9.1.3 (SAS Institute); values are expressed as means $\pm S D$ unless otherwise indicated. Section 1 in the Supplementary Appendix includes additional information regarding the calculation of the sample size and other statistical methods.

\section{RESULTS}

\section{STUDY PATIENTS}

Recruitment began in October 2004 and was completed in May 2006. After the prespecified number of adjudicated microalbuminuria events was reached, the study was stopped. The last evaluation for any patient occurred in June 2009; the median follow-up period was 3.2 years. The baseline data for participants are summarized in Table 1. The mean duration of diabetes was 6.1 years, and the mean glycated hemoglobin level was $7.7 \%$. More than $97 \%$ of the patients had at least two cardiovascular risk factors in addition to type 2 diabetes, and $67.7 \%$ had at least four.

\section{BLOOD-PRESSURE CONTROL}

The mean blood pressure during the follow-up period was $125.7 / 74.3 \mathrm{~mm} \mathrm{Hg}$ in the olmesartan group and $128.7 / 76.2 \mathrm{~mm} \mathrm{Hg}$ in the placebo group (Fig. 2A in the Supplementary Appendix). Nearly $80 \%$ of the patients in the olmesartan group and about $71 \%$ of the patients in the placebo group had a blood pressure of less than $130 / 80 \mathrm{~mm} \mathrm{Hg}$ (the target) at month 48 (Fig. 2B in the Supplementary Appendix).

At the end of the study, 24-hour ambulatory blood-pressure monitoring was performed in 568 patients (270 in the olmesartan group and 298 in the placebo group). Over the course of the study, blood pressure, as measured both in the clinic and by means of 24-hour ambulatory blood-pressure monitoring, was lower in the olmesartan group than in the placebo group (by $3.3 / 1.3 \mathrm{~mm} \mathrm{Hg}$ in clinic measurements and by 3.5/1.2 $\mathrm{mm} \mathrm{Hg}$ with 24-hour ambulatory bloodpressure monitoring).

\section{PRIMARY END POINT}

During the double-blind treatment period, microalbuminuria developed in 178 of 2160 patients in the olmesartan group for whom measurements of urinary albumin-to-creatinine ratio could be evaluated (8.2\%) and 210 of 2139 patients in the 
placebo group for whom measurements of urinary albumin-to-creatinine ratio could be evaluated $(9.8 \%)$; the median time to the onset of $\mathrm{mi-}$ croalbuminuria was 576 days in the placebo group and 722 days in the olmesartan group. The primary end point, the time to the onset of microalbuminuria (Fig. 1), was increased by $23 \%$ with olmesartan (hazard ratio for onset of microalbuminuria, 0.77 ; 95.1\% confidence interval [CI], 0.63 to $0.94 ; \mathrm{P}=0.01$ ). After adjustment for small baseline differences in the body-mass index, systolic blood pressure, and levels of high-density lipoprotein cholesterol and triglycerides (Table 1), the hazard ratio for the primary end point was 0.75 (95.1\% CI, 0.62 to 0.92; $\mathrm{P}=0.006$ ). Similar results were obtained in a prespecified per-protocol analysis and in a post hoc analysis that excluded patients who discontinued the study treatment prematurely (Table 4 in the Supplementary Appendix). The reduction in the primary end point with olmesartan remained after adjustment for differences in blood-pressure levels (Fig. 2). To identify other factors influencing the response to olmesartan treatment, an exploratory post hoc subgroup analysis was performed for several known risk factors, with dichotomization at the median for each candidate predictor variable. Baseline characteristics associated with a favorable response to olmesartan therapy included systolic blood pressure higher than $135 \mathrm{~mm} \mathrm{Hg}$, a glycated hemoglobin level of $7.3 \%$ or less, an estimated GFR of $83.79 \mathrm{ml}$ per minute per $1.73 \mathrm{~m}^{2}$ of body-surface area or less, and a urinary albuminto-creatinine ratio of more than 4 (Fig. 2).

\section{SECONDARY END POINTS}

\section{Renal Function}

The mean estimated GFR declined from $85.0 \pm 17.0$ $\mathrm{ml}$ per minute per $1.73 \mathrm{~m}^{2}$ at baseline to $80.1 \pm 18.5$ $\mathrm{ml}$ per minute per $1.73 \mathrm{~m}^{2}$ at the last assessment

\begin{tabular}{|c|c|c|c|c|}
\hline Characteristic & $\begin{array}{l}\text { Olmesartan } \\
(\mathrm{N}=\mathbf{2 2 3 2})\end{array}$ & $\begin{array}{l}\text { Placebo } \\
(\mathrm{N}=\mathbf{2 2 1 5})\end{array}$ & $\begin{array}{c}\text { Total } \\
(\mathrm{N}=4447)\end{array}$ & $P$ Value \\
\hline Male sex — no. (\%) & $1049(47.0)$ & $1003(45.3)$ & $2052(46.1)$ & $0.25 \dagger$ \\
\hline \multicolumn{5}{|l|}{ Age } \\
\hline Mean - yr & $57.7 \pm 8.8$ & $57.8 \pm 8.6$ & $57.7 \pm 8.7$ & $0.74 \dagger$ \\
\hline$\geq 65 \mathrm{yr}-$ no. (\%) & $564(25.3)$ & $554(25.0)$ & $1118(25.1)$ & $0.84 \uparrow$ \\
\hline Body-mass index $\mathbb{J}$ & $31.1 \pm 4.9$ & $30.9 \pm 4.9$ & $31.0 \pm 4.9$ & $0.05 \div$ \\
\hline \multicolumn{5}{|l|}{ Diabetes } \\
\hline Duration - yr & $6.2 \pm 6.0$ & $6.1 \pm 6.0$ & $6.1 \pm 6.0$ & $0.60 \div$ \\
\hline Prior treatment — no. (\%) & $2072(92.8)$ & $2069(93.4)$ & $4141(93.1)$ & $0.45 \dagger$ \\
\hline Smoking status - no. (\%) & & & & $0.91 \dagger$ \\
\hline Never smoked & $1367(61.2)$ & $1343(60.6)$ & $2710(60.9)$ & \\
\hline Former smoker & $452(20.3)$ & $453(20.5)$ & $905(20.4)$ & \\
\hline Current smoker & $413(18.5)$ & $419(18.9)$ & $832(18.7)$ & \\
\hline Metabolic syndrome — no. (\%) & $1834(82.2)$ & $1797(81.1)$ & $3631(81.7)$ & $0.37 \dagger$ \\
\hline \multicolumn{5}{|l|}{ Cardiovascular history — no. (\%) } \\
\hline Coronary heart disease & $564(25.3)$ & $540(24.4)$ & $1104(24.8)$ & $0.49 \dagger$ \\
\hline Myocardial infarction & $134(6.0)$ & $119(5.4)$ & $253(5.7)$ & $0.36 \dagger$ \\
\hline Stroke or TIA & $55(2.5)$ & $49(2.2)$ & $104(2.3)$ & $0.58 \dagger$ \\
\hline Peripheral vascular disease & $17(0.8)$ & $8(0.4)$ & $25(0.6)$ & $0.07 \dagger$ \\
\hline Glucose - mmol/liter & $9.0 \pm 3.1$ & $9.0 \pm 3.1$ & $9.0 \pm 3.1$ & $1.00 \div$ \\
\hline Glycated hemoglobin — \% & $7.7 \pm 1.6$ & $7.7 \pm 1.6$ & $7.7 \pm 1.6$ & $0.89 \div$ \\
\hline \multicolumn{5}{|c|}{ Blood pressure while seated $-\mathrm{mm} \mathrm{Hg}$} \\
\hline Systolic & $137 \pm 16$ & $136 \pm 15$ & $136 \pm 15$ & $0.02 \%$ \\
\hline Diastolic & $81 \pm 10$ & $80 \pm 9$ & $81 \pm 10$ & $0.11 \div$ \\
\hline
\end{tabular}




\begin{tabular}{|c|c|c|c|c|}
\hline Characteristic & $\begin{array}{l}\text { Olmesartan } \\
(\mathrm{N}=2232)\end{array}$ & $\begin{array}{l}\text { Placebo } \\
(\mathrm{N}=2215)\end{array}$ & $\begin{array}{c}\text { Total } \\
(\mathrm{N}=4447)\end{array}$ & P Value \\
\hline \multicolumn{5}{|l|}{ Urinary albumin-to-creatinine ratio\| } \\
\hline Geometric mean & $6.3 \pm 7.6$ & $5.9 \pm 6.7$ & $6.1 \pm 7.2$ & $0.06 \div$ \\
\hline Median & 4 & 3 & 4 & \\
\hline Interquartile range & $2-7$ & $2-7$ & $2-7$ & \\
\hline Serum creatinine $-\mu \mathrm{mol} /$ liter & $77.4 \pm 15.2$ & $77.5 \pm 17.1$ & $77.5 \pm 16.2$ & $0.96 \div$ \\
\hline \multicolumn{5}{|l|}{ Estimated GFR } \\
\hline Mean $-\mathrm{ml} / \mathrm{min} / 1.73 \mathrm{~m}^{2}$ & $85.0 \pm 17.0$ & $84.7 \pm 17.3$ & $84.9 \pm 17.2$ & $0.60 \%$ \\
\hline$<60 \mathrm{ml} / \mathrm{min} / 1.73 \mathrm{~m}^{2}-$ no. (\%) & $138(6.2)$ & $120(5.4)$ & $258(5.8)$ & $0.28 \dagger$ \\
\hline \multicolumn{5}{|l|}{ Cholesterol $-\mathrm{mmol} /$ liter } \\
\hline Total & $5.2 \pm 1.1$ & $5.2 \pm 1.1$ & $5.2 \pm 1.1$ & $0.76 \div$ \\
\hline LDL & $3.1 \pm 0.9$ & $3.1 \pm 0.9$ & $3.1 \pm 0.9$ & $0.31+$ \\
\hline $\mathrm{HDL}$ & $1.20 \pm 0.30$ & $1.22 \pm 0.30$ & $1.21 \pm 0.30$ & $0.02 \div$ \\
\hline Triglycerides - $\mathrm{mmol} /$ liter & $2.1 \pm 1.7$ & $2.0 \pm 1.3$ & $2.1 \pm 1.5$ & $0.02 \%$ \\
\hline
\end{tabular}

* Plus-minus values are means \pm SD. To convert the values for glucose to milligrams per deciliter, divide by 0.05551 . To convert the values for creatinine to milligrams per deciliter, divide by 88.4. To convert the values for cholesterol to milligrams per deciliter, divide by 0.02586 . To convert the values for triglycerides to milligrams per deciliter, divide by 0.01129 . HDL denotes high-density lipoprotein, LDL low-density lipoprotein, and TIA transient ischemic attack.

$\dagger$ Exploratory comparisons were performed with the use of a chi-square test.

Exploratory comparisons were performed with the use of Student's t-test.

$\int$ The body-mass index is the weight in kilograms divided by the square of the height in meters.

9 The metabolic syndrome was defined according to the criteria of the National Cholesterol Education Program (NCEP) Expert Panel on Detection, Evaluation, and Treatment of High Blood Cholesterol in Adults (Adult Treatment Panel III).

|| Albumin was measured in milligrams, and creatinine in grams. The baseline urinary albumin-to-creatinine ratio was defined as the geometric mean of the last three measurements that could be evaluated at the time of visit 1 (baseline). If insufficient measurements were available at baseline, the last measurements from the screening period were used.

$* *$ The estimated glomerular filtration rate (GFR) was calculated with the use of the abbreviated Modification of Diet in Renal Disease formula.

in the olmesartan group and from $84.7 \pm 17.3 \mathrm{ml}$ per minute per $1.73 \mathrm{~m}^{2}$ to $83.7 \pm 18.3 \mathrm{ml}$ per minute per $1.73 \mathrm{~m}^{2}$ in the placebo group $(\mathrm{P}<0.001$ for the between-group comparison of the change from baseline). End-stage renal disease did not develop in any patient; the number of patients in whom there was a doubling of the serum creatinine level was the same in each group ( $23 \mathrm{pa}$ tients, or approximately $1 \%$ ).

\section{Cardiovascular End Points}

The proportion of patients who reached the composite end point of cardiovascular complications or death from cardiovascular causes was similar in the two groups - 96 of 2232 patients (4.3\%) in the olmesartan group and 94 of 2215 patients (4.2\%) in the placebo group (Table 2). The rate of death from any cause was also very low $-1.2 \%$ (26 deaths) among patients taking olmesartan and $0.7 \%$ (15) among patients taking placebo
$(\mathrm{P}=0.10)$; in no case did the investigator report that the death was related to the study medication. The number of deaths from cardiovascular causes was higher in the olmesartan group than in the placebo group ( 15 vs. $3, \mathrm{P}=0.01$ ) (Table 2 ), owing primarily to more cases of fatal myocardial infarction (5 vs. 0 ) and sudden cardiac deaths (7 vs. 1) in the olmesartan group. The majority of deaths from cardiovascular causes (12 of 18) occurred in the subgroup of 1104 patients who had preexisting coronary heart disease. A post hoc analysis revealed an interaction between study group and preexisting coronary heart disease; among patients with preexisting coronary heart disease, there were 11 deaths from cardiovascular causes in the olmesartan group as compared with 1 in the placebo group (6.9 vs. 0.7 events per 1000 person-years, $\mathrm{P}=0.02$ ) (Table 5 in the Supplementary Appendix). A further exploratory analysis showed additional interactions: among pa- 


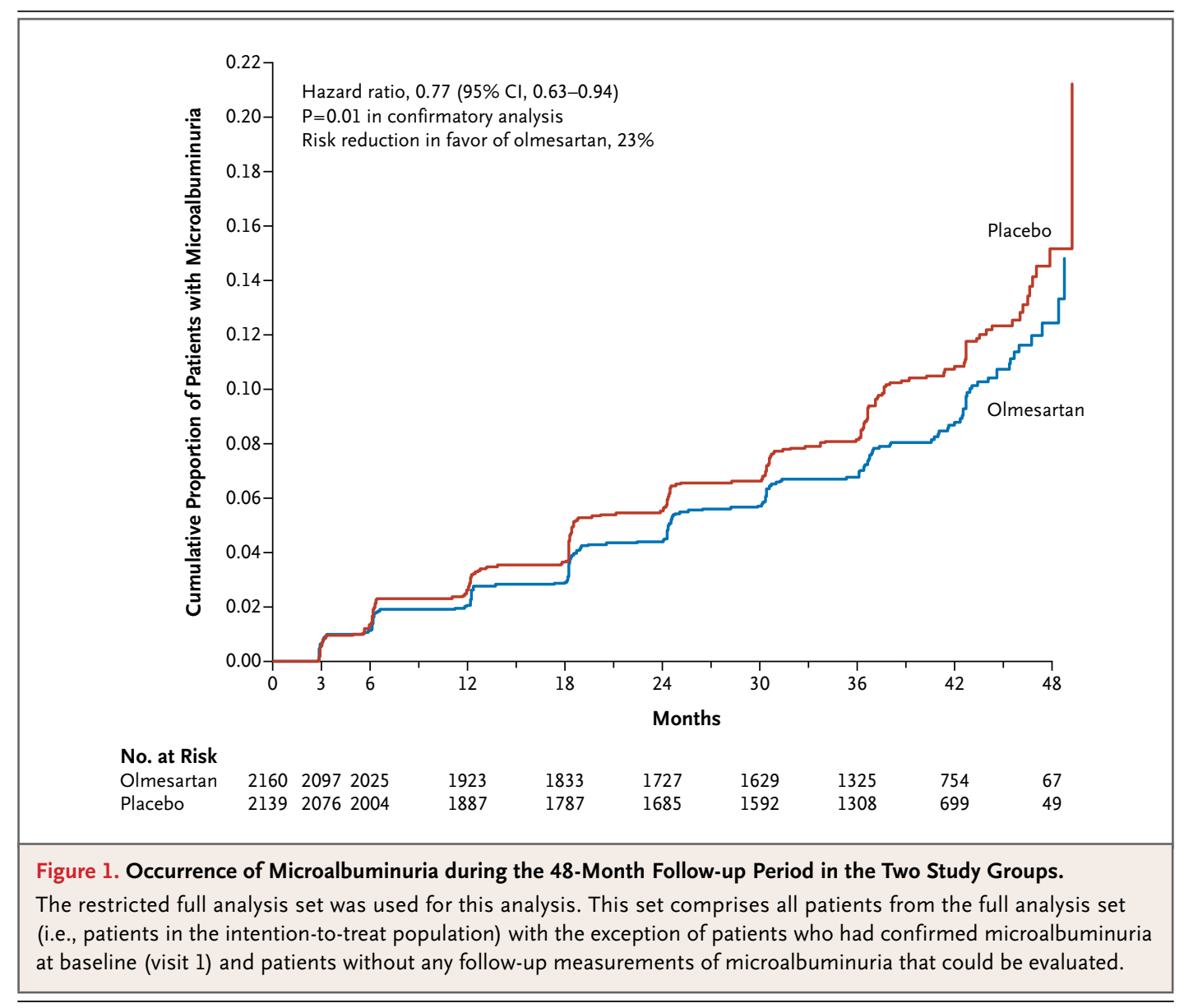

tients with preexisting coronary heart disease, those in the lowest quartile of systolic blood pressure and those in the highest quartile of reduction in systolic blood pressure during the doubleblind treatment period had the highest rates of death from cardiovascular causes (Fig. 3 in the Supplementary Appendix). No interactions with diastolic blood pressure were detected. The rate of nonfatal cardiac events was reduced with olmesartan as compared with placebo among patients without preexisting coronary heart disease but not among those with preexisting coronary heart disease (Table 5 in the Supplementary Appendix).

\section{ADVERSE EVENTS}

The number of participants in whom adverse events occurred during the treatment period was similar in the two groups (Table 3). Serious adverse events were reported in 335 patients $(15.0 \%)$ in the olmesartan group and 337 (15.2\%) in the placebo group. Drug-related adverse events occurred in 255 patients (11.4\%) receiving olmesar- $\tan$ and $166(7.5 \%)$ receiving placebo $(\mathrm{P}<0.001)$. This difference was due in part to a higher rate in the olmesartan group than in the placebo group of hypotension (58 patients vs. $6, \mathrm{P}<0.001)$ and dizziness (103 vs. $61, \mathrm{P}=0.001)$. More patients in the olmesartan group than in the placebo group were withdrawn from the study because of symptomatic hypotensive episodes (10 patients vs. 1).

\section{DISCUSSION}

There is convincing epidemiologic evidence that in patients with diabetes who also have microalbuminuria, renal impairment and cardiovascular events occur earlier than they do in patients with diabetes who do not have microalbuminuria. ${ }^{14-16}$ In this study, ARB-based therapy in patients with type 2 diabetes increased the time to the onset of microalbuminuria by $23 \%$. The baseline characteristics of patients who were most likely to benefit from ARB therapy included a higher systolic blood pressure ( $\geq 135 \mathrm{~mm} \mathrm{Hg}$ ) before treatment, 


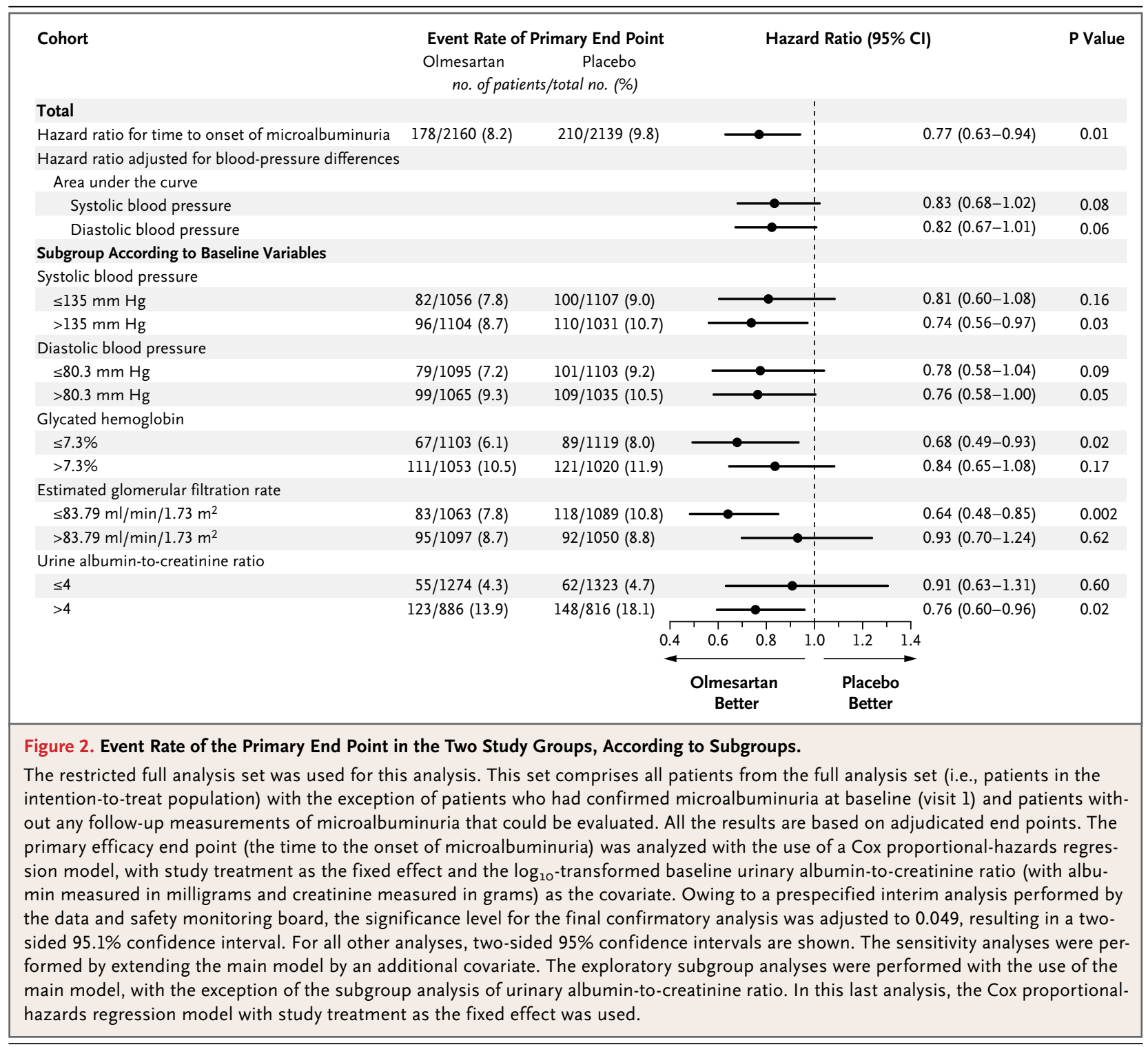

better control of diabetes (glycated hemoglobin levels of $\leq 7.3 \mathrm{mg}$ per deciliter), a lower level of renal function (estimated GFR of $<84 \mathrm{ml}$ per minute per $1.73 \mathrm{~m}^{2}$ ), and a urinary albumin-to-creatinine ratio of more than 4 . During the doubleblind treatment period, systolic and diastolic blood pressures were lower in the olmesartan group than in the placebo group by approximately 3.1/1.9 $\mathrm{mm} \mathrm{Hg}$.

Our findings extend the results of the Bergamo Nephrologic Diabetes Complications Trial (BENEDICT), ${ }^{10}$ in which ACE inhibition with trandolapril was associated with a $53 \%$ decrease in the rate of microalbuminuria in patients with hypertension and type 2 diabetes. The greater treatment effect in BENEDICT is probably due to higher baseline and follow-up blood pressures; a post hoc analysis showed that the benefit occurred in patients with a systolic blood pressure higher than $139 \mathrm{~mm}$ Hg during follow-up. ${ }^{17}$ The mean baseline blood pressure in the ROADMAP study was $136 / 81 \mathrm{~mm} \mathrm{Hg}$, and the target blood pressure ( $<130 / 80 \mathrm{~mm} \mathrm{Hg}$ ) was achieved by month 48 in nearly $80 \%$ of the patients taking olmesar$\tan$ and $71 \%$ of those taking placebo. In both groups, antihypertensive drugs other than blockers of the renin-angiotensin system were added as needed. In contrast, only $14 \%$ of the subjects 


\begin{tabular}{|c|c|c|c|c|}
\hline End Point & $\begin{array}{l}\text { Olmesartan } \\
(\mathrm{N}=2232)\end{array}$ & $\begin{array}{l}\text { Placebo } \\
(\mathrm{N}=2215)\end{array}$ & $\begin{array}{l}\text { Hazard Ratio } \\
(95 \% \mathrm{CI})\end{array}$ & P Value \\
\hline \multicolumn{5}{|c|}{ no. of patients (\%) } \\
\hline $\begin{array}{l}\text { Composite of cardiovascular complications or death from } \\
\text { cardiovascular causes }\end{array}$ & $96(4.3)$ & $94(4.2)$ & $1.00(0.75-1.33)$ & 0.99 \\
\hline Composite of death from any cause & $26(1.2)$ & $15(0.7)$ & $1.70(0.90-3.22)$ & 0.10 \\
\hline Death from cardiovascular causes & $15(0.7)$ & $3(0.1)$ & & \\
\hline Death not related to cardiovascular causes & $8(0.4)$ & $10(0.5)$ & & \\
\hline Death from unknown cause & $3(0.1)$ & $2(0.1)$ & & \\
\hline Composite of death from cardiovascular causes & $15(0.7)$ & $3(0.1)$ & $4.94(1.43-17.06)$ & 0.01 \\
\hline Sudden cardiac death & $7(0.3)$ & $1(<0.1)$ & & \\
\hline Death due to fatal myocardial infarction & $5(0.2)$ & 0 & & \\
\hline Evidence of recent myocardial infarction on autopsy & 0 & 0 & & \\
\hline Death due to congestive heart failure & 0 & 0 & & \\
\hline $\begin{array}{l}\text { Death during or after percutaneous transluminal coronary } \\
\text { angioplasty or CABG }\end{array}$ & $1(<0.1)$ & 0 & & \\
\hline Death due to fatal stroke & $2(0.1)$ & $2(0.1)$ & & \\
\hline $\begin{array}{l}\text { Composite of cardiovascular complications, excluding new- } \\
\text { onset atrial fibrillation and transient ischemic attack }\end{array}$ & $63(2.8)$ & $71(3.2)$ & $0.87(0.62-1.22)$ & 0.42 \\
\hline $\begin{array}{l}\text { Composite of new-onset atrial fibrillation or transient isch- } \\
\text { emic attack }\end{array}$ & $19(0.9)$ & $28(1.3)$ & $0.67(0.37-1.19)$ & 0.17 \\
\hline Composite of all cardiovascular complications & $81(3.6)$ & $91(4.1)$ & $0.87(0.65-1.18)$ & 0.37 \\
\hline
\end{tabular}

* All results were based on adjudicated end points. The composite secondary efficacy end points were analyzed with the use of a Cox proportional-hazards regression model with study treatment as the fixed effect. For composite end points, the time to the onset of an event was defined as the time from randomization (date of visit 1 ) to the first occurrence of any component of the composite end point. CABG denotes coronary-artery bypass grafting.

in BENEDICT reached this level of blood-pressure control. ${ }^{17}$ The results of the current study also differ somewhat from those of the Renin-Angiotensin System Study (RASS; ClinicalTrials.gov number, NCT00143949) ${ }^{12}$ and the Diabetic Retinopathy Candesartan Trials (DIRECT; Clinical Trials.gov numbers, NCT00252733, NCT00252720, and NCT00252694), ${ }^{11}$ which did not show a protective effect of ARBs or ACE inhibitors against the development of microalbuminuria in patients with type 1 diabetes and in patients with type 2 diabetes, respectively, despite a substantial reduction in blood pressure. In both of these studies, the baseline systolic blood pressure was quite low - $133 \mathrm{~mm} \mathrm{Hg}$ in DIRECT-Renal and $120 \mathrm{~mm} \mathrm{Hg}$ in RASS. ${ }^{11}$ Other studies, such as the Heart Outcomes and Prevention Evaluation (HOPE), ${ }^{18}$ the Telmisartan Randomised Assessment Study in ACE Intolerant Subjects with Cardiovascular Disease (TRANSCEND; NCT00153101), ${ }^{19}$ and the
Action in Diabetes and Vascular Disease: Preterax and Diamicron-MR Controlled Evaluation study (ADVANCE; NCT00145925), ${ }^{20}$ had previously reported a positive relation between baseline systolic blood pressure and microalbuminuria. Thus, overall, it appears that the higher the baseline blood pressure, the greater the potential benefit of an inhibitor of the renin-angiotensin system. ${ }^{10,11,18-20}$

The greater tendency for patients with a lower estimated GFR ( $<83.8 \mathrm{ml}$ per minute per $1.73 \mathrm{~m}^{2}$ ) or a urinary albumin-to-creatinine ratio at the high end of the normal range $(>4)$ to have a greater benefit with olmesartan is also of potential interest. This trend was also seen in TRANSCEND ${ }^{19}$ and may help to identify patients with type 2 diabetes and no microalbuminuria who might be potential candidates for ARB therapy.

Changes in the GFR were minimal over the course of the study; olmesartan was associated 
with a slight but significant reduction in the estimated GFR (about $4 \mathrm{ml}$ per minute per $1.73 \mathrm{~m}^{2}$ ), whereas an even smaller decrease in the estimated GFR was noted in patients treated with agents that do not block the renin-angiotensin system. It is reassuring that the rate of renal events (defined as a doubling of the serum creatinine level or the need for dialysis) was low and was identical in the olmesartan and placebo groups. There was no washout period at the end of the study, so we can only speculate about whether the drop in the estimated GFR and the lower rate of microalbuminuria in the olmesartan group represent a favorable hemodynamic (functional) response to lower glomerular pressure or an adverse underlying structural change. Recent studies suggest that a low estimated GFR and microalbuminuria are independent prognostic markers. ${ }^{14,15,21}$ In a meta-analysis, ${ }^{21}$ an estimated GFR below $60 \mathrm{ml}$ per minute per $1.73 \mathrm{~m}^{2}$ was predictive of death from any cause and of death from cardiovascular causes, but as in the present trial, there was no relationship to the risk of cardiovascular disease when the estimated GFR was 75 to $104 \mathrm{ml}$ per minute per $1.73 \mathrm{~m}^{2}$. This supports the notion that in patients with diabetes, the observed change in the rate of microalbuminuria might in the longterm be of greater importance than the small fall in the estimated GFR.

The rates of cardiovascular and cerebrovascular events in the present study were low (about $4 \%$, or 2.9 cases per 1000 person-years); they were similar to those in BENEDICT but lower than those in DIRECT-2 (8.0 cases per 1000 person years $)^{10,11}$ and substantially lower than those in studies involving patients with more advanced renal disease, such as the Reduction of Endpoints in NIDDM with the Angiotensin II Antagonist Losartan (RENAAL) study and the Irbesartan Diabetes Nephropathy Trial (IDNT), in which the rates were higher by a factor of approximately 20 , or 60 cases per 1000 person-years. ${ }^{8,9}$

Despite the low rates of cardiovascular events, there were more deaths from cardiovascular causes in the olmesartan group than in the placebo group (15 vs. $3, \mathrm{P}=0.01$ ). Owing to the very small number of affected patients, it is difficult to interpret this unexpected finding, and it may simply be related to chance. Nevertheless, because of its potential significance, several exploratory analyses were performed. Fatal cardiovascular events

\begin{tabular}{|c|c|c|c|}
\hline \multirow[t]{2}{*}{ Adverse Event } & $\begin{array}{c}\text { Olmesartan } \\
(N=2232)\end{array}$ & $\begin{array}{c}\text { Placebo } \\
(\mathrm{N}=\mathbf{2 2 1 5})\end{array}$ & P Value* \\
\hline & \multicolumn{2}{|c|}{ no. of patients (\%) } & \\
\hline At least one serious event & $335(15.0)$ & $337(15.2)$ & 0.85 \\
\hline At least one drug-related event $\dagger$ & $255(11.4)$ & $166(7.5)$ & $<0.001$ \\
\hline At least one serious drug-related event & $4(0.2)$ & $1(<0.1)$ & 0.18 \\
\hline \multicolumn{4}{|l|}{ Most frequently reported events: } \\
\hline Hypertension & $164(7.3)$ & $178(8.0)$ & 0.39 \\
\hline Headache & $100(4.5)$ & $153(6.9)$ & $<0.001$ \\
\hline Nasopharyngitis & $112(5.0)$ & $94(4.2)$ & 0.22 \\
\hline Bronchitis & $102(4.6)$ & $104(4.7)$ & 0.22 \\
\hline Influenza & $80(3.6)$ & $98(4.4)$ & 0.15 \\
\hline Back pain & $96(4.3)$ & $75(3.4)$ & 0.11 \\
\hline Dizziness & $103(4.6)$ & $61(2.8)$ & 0.001 \\
\hline Peripheral edema & $60(2.7)$ & $86(3.9)$ & 0.03 \\
\hline \multicolumn{4}{|l|}{ Events of special interest } \\
\hline Hypotension & $58(2.6)$ & $6(0.3)$ & $<0.001$ \\
\hline Hyperkalemia & $11(0.5)$ & $8(0.4)$ & 0.50 \\
\hline
\end{tabular}

$* \mathrm{P}$ values were calculated with the use of a chi-square test.

$\dagger$ An event was considered to be drug-related if, according to the investigator's judgment, the event was definitely, probably, or possibly related to the treatment or if information on the relationship of the event to the study treatment was missing.

$\mp$ Events included in this category are those that occurred in at least $3 \%$ of the patients in either study group; adverse events that were part of the primary or secondary efficacy end points are not shown.

were more common in the olmesartan group than in the placebo group among patients with known preexisting coronary heart disease (11 events vs. 1 with placebo, $\mathrm{P}=0.03$ ), but the rates were similar in the two groups among patients without preexisting coronary disease. There was also a trend toward more fatal events in patients with preexisting coronary heart disease who were either in the lowest quartile of blood pressure or in the highest quartile of blood-pressure reduction during follow-up. Therefore, excessive reduction of blood pressure in some high-risk patients may confer a predisposition to an increased risk of death, a finding that is consistent with the well-known, somewhat controversial "J-curve effect"; however, a direct effect of olmesartan cannot be ruled out.

In the Olmesartan Reducing Incidence of End Stage Renal Disease in Diabetic Nephropathy Trial (ORIENT; NCT00141453), which involved 
patients with diabetic nephropathy, the addition of olmesartan to preexisting antihypertensive treatment was associated with a higher rate of death from cardiovascular causes (10 cases vs. 3 cases; www.fda.gov/Drugs/DrugSafety/Postmarket DrugSafetyInformationforPatientsandProviders/ ucm 215222.htm). Because of these findings in ROADMAP and ORIENT, the Food and Drug Administration is currently reviewing existing data. Nevertheless, the rate of nonfatal cardiovascular events was not increased with olmesartan among patients without preexisting coronary heart disease. The results of the current study must also be viewed in the context of the many other studies of renal and cardiovascular outcomes that have shown that ARBs have a beneficial effect on cardiovascular disease. ${ }^{22,23}$

In the Ongoing Telmisartan Alone and in Combination with Ramipril Global Endpoint Trial (ONTARGET; NCT00153101) ${ }^{24}$ and the International Verapamil SR Trandolapril Study (INVEST; NCT00133692), ${ }^{25}$ an increase in the rate of death from cardiovascular causes was observed among patients with known coronary heart disease if the systolic blood pressure was below $120 \mathrm{~mm} \mathrm{Hg}$ during the time the patient was receiving therapy with ACE inhibitors or ARBs (in ONTARGET) or calcium-channel blockers or beta-blockers (in INVEST); thus, any adverse effect appears to be related more closely to the achieved blood pressure than the class of drug that was used. The concern about potential overtreatment is reflected in the guidelines published by the European Society of Hypertension, which state that physicians should avoid lowering blood pressure excessively (i.e., to values below $120 / 70 \mathrm{~mm} \mathrm{Hg}$ ) in persons with underlying cardiovascular disease. ${ }^{26}$

Our study has certain limitations. First, it is not possible to draw definite conclusions from a short-term prevention study about the way in which changes in microalbuminuria may affect the rates of renal and cardiovascular event rates in the long term. During the study itself, the follow-up period was too short. Second, the rate of premature withdrawals in both study groups was high (about 23\% in both groups); however, it seems unlikely that withdrawals affected the overall findings of the study, since an exploratory analysis excluding these patients did not affect the primary end point. Third, although the differences in blood pressure between the treatment groups may have contributed to the primary outcome, and the benefit was greater in patients with higher baseline blood pressure, adjustment of the analysis for differences in blood pressure during the study did not eliminate the improvement in the primary end point that was seen with olmesartan.

In summary, this trial suggests that olmesar$\tan$ increases the time to the onset of microalbuminuria in patients with type 2 diabetes, even when blood-pressure control is excellent according to current recommendations.

\section{Supported by Daiichi Sankyo.}

Dr. Haller reports receiving payment for board membership from Novartis, consulting fees from Bayer Schering Pharma and Daiichi Sankyo, lecture fees from Bayer Schering Pharma, Roche, and Menarini, payment for development of educational presentations from Daiichi Sankyo and Bayer Schering Pharma, and travel support from Amgen and Daiichi Sankyo; Dr. Ito, consulting fees from Novartis Pharmaceuticals and Takeda Pharmaceutical, grant support paid to his institution, Tohoku University Graduate School of Medicine, from Banyu Pharmaceutical, Takeda Pharmaceutical, Astellas Pharma, Boehringer Ingelheim, Novartis Pharmaceuticals, Shionogi, and Dainippon Sumitomo Pharma, and lecture fees from Banyu Pharmaceutical, Takeda Pharmaceutical, Astellas Pharma, Boehringer Ingelheim, Novartis Pharmaceuticals, Shionogi, and Dainippon Sumitomo Pharma; Dr. Izzo, consulting and lecture fees from Daiichi Sankyo; Dr. Januszewicz, lecture fees from Boehringer Ingelheim, Novartis, Adamed, Bayer Healthcare, Sanofi-Aventis, Sandoz, Merck, and Krka; Dr. Katayama, grant support from Daiichi Sankyo, Merck, Novartis, and Boehringer Ingelheim and lecture fees from Daiichi Sankyo, Merck, Novartis, and Astellas Pharma; Dr. Menne, lecture fees from Berlin-Chemie, Novartis, and Daiichi Sankyo; Dr. Mimran, payment for board membership and consulting fees from Daiichi Sankyo and Servier; Dr. Ruilope, payment for board membership and consulting and lecture fees from Daiichi Sankyo; Dr. Rump, consulting and lecture fees from Daiichi Sankyo; Dr. Viberti, payment for board membership from GlaxoSmithKline, Novartis, and Pfizer and lecture fees from Guidotti and Malesci; and Dr. Ritz, payment for board membership and lecture fees from Abbott and consulting fees from Hexal. No other potential conflict of interest relevant to this article was reported.

Disclosure forms provided by the authors are available with the full text of this article at NEJM.org.
REFERENCES

1. USRDS: the United States Renal Data System. Am J Kidney Dis 2003;42:Suppl 5: 1-230.

2. Bakris GL, Williams M, Dworkin L, et al. Preserving renal function in adults with hypertension and diabetes: a con- sensus approach. Am J Kidney Dis 2000; 36:646-61.

3. Mogensen CE. Urinary albumin excretion in early and long-term juvenile diabetes. Scand J Clin Lab Invest 1971;28: 183-93.
4. Viberti GC, Hill RD, Jarrett RJ, Argyropoulos A, Mahmud U, Keen H. Microalbuminuria as a predictor of clinical nephropathy in insulin-dependent diabetes mellitus. Lancet 1982;1:1430-2.

5. de Zeeuw D, Parving $\mathrm{HH}$, Henning 
RH. Microalbuminuria as an early marker for cardiovascular disease. J Am Soc Nephrol 2006;17:2100-5.

6. Mancia G, De Backer G, Dominiczak A, et al. 2007 Guidelines for the management of arterial hypertension: The Task Force for the Management of Arterial Hypertension of the European Society of Hypertension (ESH) and of the European Society of Cardiology (ESC). J Hypertens 2007;25:1105-87. [Erratum, J Hypertens 2007;25:1749.]

7. Standards of medical care in diabetes - 2009. Diabetes Care 2009;32:Suppl 1: S13-S61.

8. Brenner BM, Cooper ME, de Zeeuw D, et al. Effects of losartan on renal and cardiovascular outcomes in patients with type 2 diabetes and nephropathy. $\mathrm{N}$ Engl J Med 2001;345:861-9.

9. Lewis EJ, Hunsicker LG, Clarke WR, et al. Renoprotective effect of the angiotensin-receptor antagonist irbesartan in patients with nephropathy due to type 2 diabetes. N Engl J Med 2001;345:851-60.

10. Ruggenenti P, Fassi A, Ilieva AP, et al. Preventing microalbuminuria in type 2 diabetes. N Engl J Med 2004;351:194151.

11. Bilous R, Chaturvedi N, Sj申lie AK, et al. Effect of candesartan on microalbuminuria and albumin excretion rate in diabetes: three randomized trials. Ann Intern Med 2009;151:11-20.

12. Mauer M, Zinman B, Gardiner R, et al. Renal and retinal effects of enalapril and losartan in type 1 diabetes. $\mathrm{N}$ Engl J Med 2009;361:40-51.
13. Haller H, Viberti GC, Mimran A, et al. Preventing microalbuminuria in patients with diabetes: rationale and design of the Randomised Olmesartan and Diabetes Microalbuminuria Prevention (ROADMAP) study. J Hypertens 2006;24:403-8.

14. Hemmelgarn BR, Manns BJ, Lloyd A, et al. Relation between kidney function, proteinuria, and adverse outcomes. JAMA 2010;303:423-9.

15. Hallan SI, Ritz E, Lydersen S, Romundstad S, Kvenild K, Orth SR. Combining GFR and albuminuria to classify CKD improves prediction of ESRD. J Am Soc Nephrol 2009;20:1069-77.

16. Newman DJ, Mattock MB, Dawnay $A B$, et al. Systematic review on urine albumin testing for early detection of diabetic complications. Health Technol Assess 2005;9(30):iii-vi, xiii-163.

17. Ruggenenti P, Perna A, Ganeva M, Ene-Iordache B, Remuzzi G. Impact of blood pressure control and angiotensinconverting enzyme inhibitor therapy on new-onset microalbuminuria in type 2 diabetes: a post hoc analysis of the BENEDICT trial. J Am Soc Nephrol 2006;17:3472-81. 18. Mann JF, Gerstein HC, Yi QL, et al. Development of renal disease in people at high cardiovascular risk: results of the HOPE randomized study. J Am Soc Nephrol 2003;14:641-7.

19. Mann JF, Schmieder RE, Dyal L, et al. Effect of telmisartan on renal outcomes: a randomized trial. Ann Intern Med 2009; 151:1-10.

20. de Galan BE, Perkovic V, Ninomiya T, et al. Lowering blood pressure reduces renal events in type 2 diabetes. J Am Soc Nephrol 2009;20:883-92.

21. Matsushita K, van der Velde M, Astor $\mathrm{BC}$, et al. Association of estimated glomerular filtration rate and albuminuria with all-cause and cardiovascular mortality in general population cohorts: a collaborative meta-analysis. Lancet 2010;375: 2073-81.

22. Lindholm LH, Ibsen H, Dahlöf B, et al. Cardiovascular morbidity and mortality in patients with diabetes in the Losartan Intervention For Endpoint reduction in hypertension study (LIFE): a randomised trial against atenolol. Lancet 2002;359:1004-10.

23. The ONTARGET Investigators. Telmisartan, ramipril, or both in patients at high risk for vascular events. N Engl J Med 2008;358:1547-59.

24. Sleight $P$, Redon J, Verdecchia P, et al. Prognostic value of blood pressure in patients with high vascular risk in the Ongoing Telmisartan Alone and in Combination with Ramipril Global Endpoint Trial study. J Hypertens 2009;27:1360-9.

25. Messerli FH, Mancia G, Conti CR, et al. Dogma disputed: can aggressively lowering blood pressure in hypertensive patients with coronary artery disease be dangerous? Ann Intern Med 2006;144:88493.

26. Mancia G, Laurent S, Agabiti-Rosei E, et al. Reappraisal of European guidelines on hypertension management: a European Society of Hypertension Task Force document. J Hypertens 2009;27:2121-58. Copyright (c) 2011 Massachusetts Medical Society.

MY NEJM IN THE JOURNAL ONLINE

Individual subscribers can store articles and searches using a feature on the Journal's Web site (NEJM.org) called "My NEJM."

Each article and search result links to this feature. Users can create personal folders and move articles into them for convenient retrieval later. 